\title{
Adsorption Analysis of Fluoride Removal Using Graphene Oxide/Eggshell Adsorbent
}

\author{
Norhusna Mohamad Nor ${ }^{1, *}$, Nur Hidayahtul Nazrah Kamil ${ }^{1}$, Amirul Izan Mansor ${ }^{1}$, and Hawaiah Imam \\ Maarof $^{2}$
}

${ }^{1}$ Faculty of Chemical Engineering, Universiti Teknologi MARA, Cawangan Pulau Pinang, 13500 Permatang Pauh, Pulau Pinang, Malaysia

${ }^{2}$ Faculty of Chemical Engineering, Universiti Teknologi MARA, 40450 Shah Alam, Selangor, Malaysia

*Corresponding author:

tel: $+604-3822539$

email:norhusna8711@ppinang.uitm.edu.my

Received: February 8, 2019

Accepted: July 12, 2019

DOI: $10.22146 /$ ijc. 43481

\begin{abstract}
Graphene oxide with eggshells (GO/ES) adsorbent has been studied for fluoride ions $\left(F^{-}\right)$removal. An adsorption study was conducted in batch experiments at different adsorption parameters, which are initial $F^{-}$concentration, contact time, and temperature. The effects of these adsorption parameters towards $F^{-}$removal by using GO/ES adsorbent were investigated. The adsorption parameters were then analyzed with adsorption isotherms (Langmuir and Freundlich), kinetics (pseudo-first-order and second-order) and thermodynamic studies. Under various parameters, GO/ES is proven as an effective adsorbent with an adsorption capacity of $F^{-}$are up to $48 \mathrm{mg} / \mathrm{g}$. The experimental data were satisfactorily fitted with Langmuir isotherm, which illustrated the monolayer pattern of $\mathrm{F}^{-}$adsorption into GO/ES adsorbent. The adsorption kinetic analysis indicated that the adsorption data could be well described by Pseudo-second-order kinetic model, which indicated the chemisorption process, while thermodynamic studies revealed that the adsorption of $F^{-}$was an exothermic process.
\end{abstract}

Keywords: graphene oxide; eggshell; fluoride; adsorption; isotherms; thermodynamics; kinetics

\section{- INTRODUCTION}

Contamination of fluoride $\left(\mathrm{F}^{-}\right)$in groundwater has been identified as a serious problem, which contributes to adverse effects on human health, aquatic life and indirectly to the environment as well. This occurrence is contributed by various sources, such as effluent from industrial activities, agricultural activities, and existing geological formation [1]. World Health Organization (WHO) has classified $\mathrm{F}^{-}$as one of the main contaminants in water; hence, a maximum allowable limit for $\mathrm{F}^{-}$in drinking water is suggested to be as low as $1.5 \mathrm{mg} / \mathrm{L}$ [3]. In addition, the Ministry of Health Malaysia has also set regulation for the National Standard for Drinking Water Quality, where it must be below than $0.4-0.6 \mathrm{ppm}$ of $\mathrm{F}^{-}$concentration [4]. According to the Environmental Quality (Industrial Effluent) regulations, the permissible $\mathrm{F}^{-}$limit for industrial effluent in standard A and B are $2.0 \mathrm{mg} / \mathrm{L}$ and
$5.0 \mathrm{mg} / \mathrm{L}$, respectively [5]. Therefore, the wastewater effluent discharged from all industry must meet the allowable limit. Hence, concerning human health, developing efficient methods in $\mathrm{F}^{-}$removal is significant to ensure $\mathrm{F}^{-}$concentration is within acceptable limits.

The removal of $\mathrm{F}^{-}$has become a great concern globally due to its toxic effect on the water towards humans and the environment. Various treatment methods are available for $\mathrm{F}^{-}$removal, for instance, ion exchange, chemical precipitation, fluidized-bed precipitation, aluminum-solubility, membrane filtration, electrochemical method, and adsorption [1-2]. Among those methods, the adsorption process has been identified as the most efficient and economical method to be used in $\mathrm{F}^{-}$removal [6]. The efficiency of adsorption depends on the type of adsorbents used, where high removal of $\mathrm{F}^{-}$is anticipated based on the excellent development of the adsorptive materials. There are 
many types of adsorbents that have been used for fluoride removal, such as activated carbon, biochar, raw biomass, fly ash, calcium-containing materials, and graphene oxide (GO) [1].

Calcium containing materials such as bone, eggshells, calcium carbonate $\left(\mathrm{CaCO}_{3}\right)$, and seashells have been used by researchers as adsorbents for $\mathrm{F}^{-}$removal, due to their strong affinity towards the target pollutant [7]. GO is the combination of graphene and oxidizing agents, producing hydrophilic materials, and expands layer of separation [8]. The unique properties of GO are, it is a promising material for adsorption of $\mathrm{F}^{-}$, due to its structure which can be altered, and it has excellent chemical, thermal and mechanical stability [8-9]. Furthermore, it also offers high surface areas with abundant binding sites, which is suitable for further modification. In this research work, the modification of $\mathrm{GO}$ with calcium-containing material, which is eggshells (ES) will be discussed in detail. ES has been selected, because of its low-cost material (waste) which is abundantly available, and its composition consists of a high percentage of $\mathrm{CaCO}_{3}$. Thus, its combination with $\mathrm{GO}$ is a perfect match for $\mathrm{F}^{-}$removal. The objective of this work is to investigate the effects of various adsorption parameters and adsorption analysis of $\mathrm{F}^{-}$removal by using GO/ES adsorbent.

\section{- EXPERIMENTAL SECTION}

\section{Materials}

Eggshells (ES) were obtained from a nearby cafeteria, UiTM Cawangan Pulau Pinang. Chemicals used for the synthesis of graphene oxide (GO) were graphite powder (99.99\%), sodium nitrate $\left(\mathrm{NaNO}_{3} 98 \%\right)$, sulphuric acid $\left(\mathrm{H}_{2} \mathrm{SO}_{4} 98 \%\right)$, potassium permanganate, $\left(\mathrm{KMnO}_{4}\right)$, hydrogen peroxide $\left(\mathrm{H}_{2} \mathrm{O}_{2}\right)$, and hydrochloric acid $(\mathrm{HCl})$. As for the batch adsorption experiment, the chemical used was sodium fluoride $(\mathrm{NaF})$.

\section{Procedure}

\section{Synthesis of GO/ES adsorbent}

Graphene oxide (GO) was prepared by using a modified Hummer's method [10]. $2.5 \mathrm{~g}$ of graphite powder and $1.25 \mathrm{~g}$ of $\mathrm{NaNO}_{3}$ were added together with
$60 \mathrm{~mL}$ of $\mathrm{H}_{2} \mathrm{SO}_{4}$ in a conical flask with continuous stirring for $2 \mathrm{~h}$ at constant temperature $\left(10^{\circ} \mathrm{C}\right) . \mathrm{KMnO}_{4}$ $(7.5 \mathrm{~g})$ was added into the mixture, where the reaction temperature was controlled to be lower than $10^{\circ} \mathrm{C}$. The mixture was continued stirred at $30^{\circ} \mathrm{C}$ for $2 \mathrm{~h}$ until the solution becomes pasty brownish. Next, $135 \mathrm{~mL}$ of deionized (DI) water was added slowly into the mixture. The reaction temperature was increased to $50{ }^{\circ} \mathrm{C}$ until the brownish color obtained. Finally, the mixture was terminated by the addition of $25 \mathrm{~mL}$ of $\mathrm{H}_{2} \mathrm{O}_{2}$, which turned the mixture into gold-yellow color. The mixture was filtered and washed with $400 \mathrm{~mL}$ of $\mathrm{HCl}$ and DI water repeatedly to remove any impurities. Then, it was dried in a drying oven at $60^{\circ} \mathrm{C}$ for $24 \mathrm{~h}$ [11].

Pre-treatment of ES was done by washing it with DI water and drying in an oven at $45^{\circ} \mathrm{C}$ for overnight. Then, ES was ground into a powder form, to obtain $250 \mu \mathrm{m}$ size of particles size. One gram of GO in a slurry form was added into a beaker containing $300 \mathrm{~mL}$ of DI water and sonicated for $1 \mathrm{~h}$ at $45^{\circ} \mathrm{C}$. Then, $5 \mathrm{~g}$ of ES was added into the mixture. After $1 \mathrm{~h}$, the suspension was collected and centrifuged for $15 \mathrm{~min}$ at $3000 \mathrm{rpm}$ and dried at $60^{\circ} \mathrm{C}$ overnight [12].

\section{Batch experimental of fluoride removal}

The effects of adsorption parameters (i.e., $\mathrm{F}^{-}$initial concentration, contact time, and temperature) were conducted via a batch experiment. A stock solution of $1000 \mathrm{mg} / \mathrm{L}$ of fluoride was prepared by dissolving $1 \mathrm{~g}$ of $\mathrm{NaF}$ in $1 \mathrm{~L}$ of distilled water. The stock solution was diluted with distilled water to an achieved a concentration of $30 \mathrm{mg} / \mathrm{L}$. A $200 \mathrm{~mL}$ of $\mathrm{NaF}$ stock solution was tested with $0.05 \mathrm{~g}$ of $\mathrm{GO} / \mathrm{ES}$ adsorbent at $25^{\circ} \mathrm{C}$. The mixture was shaken by using an orbital shaker with $200 \mathrm{rpm}$ for $60 \mathrm{~min}$. The adsorbent was filtered through a $0.45 \mu \mathrm{m}$ membrane filter. The steps were repeated at different concentrations $(30,40,50,60,70 \mathrm{mg} / \mathrm{L})$ contact times $(30,60,90,120 \mathrm{~min})$ and temperatures $\left(25,45,60,75^{\circ} \mathrm{C}\right)$. $\mathrm{F}^{-}$final concentrations were measured by using DR 2800 Spectrophotometer before and after adsorption. SPADNS reagent was used as a standard to detect $\mathrm{F}^{-}$ concentration in samples. The adsorption capacity and percentage removal (\%R) of $\mathrm{F}^{-}$were calculated by using Eq. (1) and (2), respectively. 
$\mathrm{Q}_{\mathrm{e}}=\left[\frac{\mathrm{C}_{0}-\mathrm{C}_{\mathrm{t}}}{\mathrm{m}}\right]$

$\%$ Removal $=\left[\frac{\mathrm{C}_{0}-\mathrm{C}_{\mathrm{t}}}{\mathrm{C}_{0}}\right] \times 100$

where $\mathrm{Q}_{\mathrm{e}}$ is $\mathrm{F}^{-}$adsorbed per unit mass of adsorbent $(\mathrm{mg} / \mathrm{g}), \mathrm{C}_{\mathrm{t}}$ is the final concentration of $\mathrm{F}^{-}$at equilibrium $(\mathrm{mg} / \mathrm{L}), \mathrm{C}_{0}$ is an initial concentration of $\mathrm{F}^{-}(\mathrm{mg} / \mathrm{L})$ and $\mathrm{m}$ is mass of adsorbent $(\mathrm{g} / \mathrm{L})$.

\section{Adsorption isotherms}

The analysis of adsorption isotherms were linearized as in Eq. (3) and (4) that represent Langmuir and Freundlich isotherms, respectively.

$\frac{\mathrm{C}_{\mathrm{e}}}{\mathrm{q}_{\mathrm{e}}}=\frac{\mathrm{C}_{\mathrm{e}}}{\mathrm{q}_{\max }}+\frac{1}{\mathrm{q}_{\max } \mathrm{K}_{\mathrm{L}}}$

$\log \mathrm{q}_{\mathrm{e}}=\log \mathrm{K}_{\mathrm{F}}+\frac{1}{\mathrm{n}} \log \mathrm{C}_{\mathrm{e}}$

where $C_{e}$ is equilibrium concentration of fluoride $(\mathrm{mg} / \mathrm{L})$, $\mathrm{q}_{\mathrm{e}}$ is amount of fluoride adsorbed at equilibrium per gram of adsorbent $(\mathrm{mg} / \mathrm{g}), \mathrm{q}_{\max }$ is adsorption for a complete monolayer $(\mathrm{mg} / \mathrm{g}), \mathrm{k}_{\mathrm{L}}$ is a constant value of Langmuir $(\mathrm{L} / \mathrm{mg}), K_{\mathrm{F}}$ is Freundlich constant $(\mathrm{L} / \mathrm{mg})$, and $1 / \mathrm{n}$ is adsorption intensity.

\section{Adsorption kinetics}

The pseudo-first-order and pseudo-second-order adsorption kinetic models were used to investigate the adsorption kinetics of fluoride and to quantify the extent of uptake in the adsorption process, as shown in Eq. (5) and (6), respectively.

$\log \left(\mathrm{q}_{\mathrm{e}}-\mathrm{q}\right)=\log \mathrm{q}_{\mathrm{e}}-\frac{\mathrm{K}_{1} \mathrm{t}}{2.303}$

$\frac{\mathrm{t}}{\mathrm{q}}=\frac{1}{\mathrm{~K}_{2} \mathrm{q}_{\mathrm{e}}{ }^{2}}+\left(\frac{1}{\mathrm{q}_{\mathrm{e}}}\right) \mathrm{t}$

where $\mathrm{q}_{\mathrm{e}}$ is equilibrium adsorption capacity $(\mathrm{mg} / \mathrm{g}), \mathrm{q}$ is adsorption capacity at times $(\mathrm{mg} / \mathrm{g}), \mathrm{K}_{1}$ is rate constant of pseudo-first-order adsorption, $K_{2}$ is rate constant of pseudo-first-order adsorption, and $\mathrm{t}$ is time.

\section{Adsorption thermodynamics}

Thermodynamic parameters such as standard free energy change $\left(\Delta \mathrm{G}^{\circ}\right)$, enthalpy change $\left(\Delta \mathrm{H}^{\circ}\right)$ and entropy change $\left(\Delta S^{\circ}\right)$ were calculated to evaluate the spontaneous nature and the thermodynamic feasibility of the adsorption process [13]. The value of the equilibrium constant, $\mathrm{K}_{0}$, is calculated by using Eq. (7). The dependence of temperature on the adsorption of fluoride ions onto GO/ES adsorbent was evaluated using Eq. (8) and (9).

$\mathrm{K}_{0}=\frac{\mathrm{C}_{0}}{\mathrm{C}_{\mathrm{e}}}$

$\Delta \mathrm{G}^{\circ}=-\mathrm{RT} \ln \mathrm{K}_{0}$

$\operatorname{LogK}_{0}=\frac{\Delta \mathrm{S}^{\circ}}{2.303 \mathrm{R}}-\frac{\Delta \mathrm{H}^{\circ}}{2.303 \mathrm{RT}}$

where $C_{0}$ is the initial amount of adsorbate in solution $(\mathrm{mg} / \mathrm{L}), \mathrm{C}_{\mathrm{e}}$ is equilibrium amount of adsorbate in solution $(\mathrm{mg} / \mathrm{L}) \mathrm{R}$ is universal gas constant $(\mathrm{J} / \mathrm{mol} . \mathrm{K})$, and $\mathrm{T}$ is temperature $(\mathrm{K})$.

\section{- RESULTS AND DISCUSSION}

Batch adsorption studies were conducted on various adsorption parameters, which are $\mathrm{F}^{-}$initial concentration, temperature, and contact time. The results of adsorption capacity and \% removal of $\mathrm{F}^{-}$at different adsorption parameters are shown in Fig. 1, respectively. Details discussion on the effect of each parameter will be discussed in the following subsections. According to Kashi et al. the eggshell is a promising material to be used as an adsorbent for $\mathrm{F}^{-}$removal, which the fluoride removal was up to $100 \%$ [7]. The combination of eggshell and GO is expected to produce an excellent adsorbent since the use of GO modified with magnetic iron and aluminum oxide done by Liu et al. could remove $\mathrm{F}^{-}$up to $64 \mathrm{mg} / \mathrm{g}$ [11]. The combination of GO with eggshells (GO/ES) in this research work can adsorb up until $56 \mathrm{mg} / \mathrm{g}$.

\section{Effect of Initial Fluoride Concentration}

To study the effect of initial $\mathrm{F}^{-}$concentration, the experiments were carried out with $0.05 \mathrm{~g}$ of adsorbent dosage, $60 \mathrm{~min}$ of contact time, and $25^{\circ} \mathrm{C}$ of temperature. The $\%$ removal of $\mathrm{F}^{-}$as shown in Fig. 1(a) decreases as $\mathrm{F}^{-}$ initial concentration increases. However, the adsorption capacities of $\mathrm{F}^{-}$shown in Fig. 1 do not vary significantly, which are in the range of $44-46 \mathrm{mg} / \mathrm{g}$. This is due to the vacant sites in GO/ES adsorbent which are capable of adsorbing up to a certain capacity, even though the higher initial concentration of $\mathrm{F}^{-}$was introduced. The ratio of $\mathrm{F}^{-}$to the number of available sites in GO/ES adsorbent is constant, where the vacant sites were saturated with $\mathrm{F}^{-}$ 
at certain concentration $[7,13]$. As the concentration gradient of $\mathrm{F}^{-}$increased, the driving force will increase to overcome the mass transfer resistance of $\mathrm{F}^{-}$from aqueous solution into a solid phase, which increases the adsorption equilibrium of GO/ES adsorbent until it achieved a saturated state. At the same time, this occurrence also resulted from the fixed adsorbent dosage used, where available vacant sites are limit with the increase of $\mathrm{F}^{-}$ initial concentration. These results are in agreement with the study done by Bhaumik et al. [13], where an increase of $\mathrm{F}^{-}$concentration resulted in the decrement of the $\%$ removal.

\section{Effect of Contact Time}

The effect of contact time was varied at a given initial concentration $(25 \mathrm{mg} / \mathrm{L})$, adsorbent dosage $(0.05 \mathrm{~g})$ and temperature $\left(25^{\circ} \mathrm{C}\right)$. As illustrated in Fig. $1(\mathrm{~b})$, the $\%$ removal of $\mathrm{F}^{-}$increased as contact time increases from 30 to $90 \mathrm{~min}$ and remained constant afterward, where no significant changes are observed from 90 to $120 \mathrm{~min}$. A similar trend is shown by the adsorption capacity of $\mathrm{F}^{-}$in Fig. 1, where the values increase from 36 to $55 \mathrm{mg} / \mathrm{g}$ and start to reach equilibrium from $55-56 \mathrm{mg} / \mathrm{g}$. The modification of ES into GO resulted in a large number of active binding sites, where the positive charge on $\mathrm{Ca}^{2+}$ extracted from $\mathrm{CaCO}_{3}$ may be existed on GO's surface, thus enhancing the adsorption rate of $\mathrm{F}^{-}$that is having negative charge [7]. Increasing the availability of active binding sites on the adsorbent surface might result in a high removal of $\mathrm{F}^{-}$. In this work, the adsorption of $\mathrm{F}^{-}$to reach equilibrium is started after $90 \mathrm{~min}$, which is slower compared to other previous works [13-14]. It is presumed that the diffusion process of $\mathrm{F}^{-}$from the bulk solution to the GO/ES adsorbent's surface is controlled by the affinity of $\mathrm{F}^{-}$towards $\mathrm{GO} / \mathrm{ES}$ 's active binding sites, where longer time is needed for adsorption to reach equilibrium.

\section{Effect of Temperature}

The adsorption temperature of $\mathrm{F}^{-}$was varied at 25 , 45, 60 and $75{ }^{\circ} \mathrm{C}$, with $25 \mathrm{mg} / \mathrm{L}$ of $\mathrm{F}^{-}$initial concentration, $0.05 \mathrm{~g}$ of adsorbent dosage and $60 \mathrm{~min}$ of contact time. Fig. 1 (c) showed that the $\%$ removal of $\mathrm{F}^{-}$ decreased with increase in temperature. This indicates that low temperature $\left(25{ }^{\circ} \mathrm{C}\right)$ is favorable for $\mathrm{F}^{-}$ adsorption, which the highest $\%$ removal and adsorption capacity obtained were $48.12 \%$ and $48.12 \mathrm{mg} / \mathrm{g}$, respectively. Inefficient removal of $\mathrm{F}^{-}$was observed at elevated temperature, starting from 60 to $75^{\circ} \mathrm{C}$. Possibly, this is because high energy was received by $\mathrm{F}^{-}$, resulting in exciting movement of $\mathrm{F}^{-}$molecules. Hence, the tendency of the molecules to escape from active binding sites is greater, which lead to less $\mathrm{F}^{-}$being adsorbed into $\mathrm{GO} / \mathrm{ES}$ adsorbent as the temperature is increased [15]. Therefore, lower temperature (less than $60{ }^{\circ} \mathrm{C}$ ) is anticipated to be used to achieve high removal of $\mathrm{F}^{-}$, since sufficient energy will be delivered to the molecules. Indirectly, $\mathrm{F}^{-}$will be steadily diffused into GO/ES's active binding sites without any resistances from the exciting movement of the molecules.
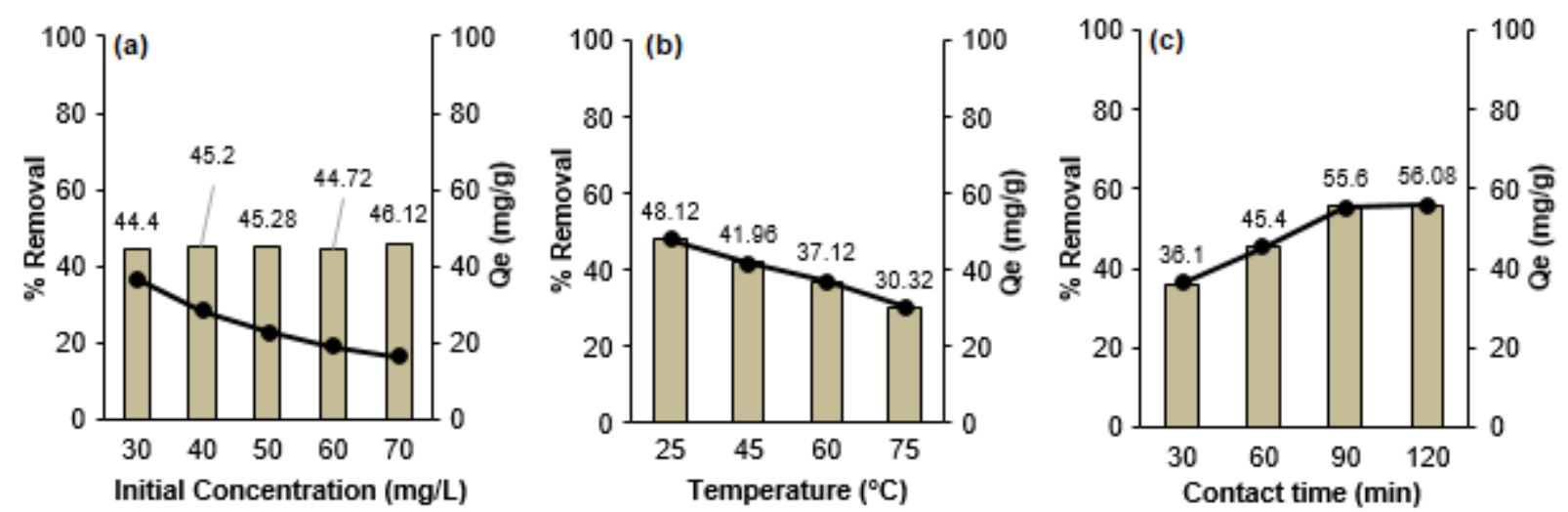

Fig 1. Effect of (a) initial concentration (b) contact time and (c) temperature on $\mathrm{F}^{-}$percentage removal by using GO/ES adsorbent 


\section{Adsorption Isotherms}

In this study, the adsorption mechanism of $\mathrm{F}^{-}$onto $\mathrm{GO} / \mathrm{ES}$ adsorbent is further explained by using isotherm models, which are Langmuir and Freundlich. These isotherms are capable to describe the interaction between $\mathrm{F}^{-}$adsorbate and GO/ES adsorbent, which include homogeneity of the adsorbent and type of adsorption coverage [9]. The results of the isotherms are illustrated in Fig. 2, where higher $\mathrm{R}^{2}$ value was obtained via the Langmuir isotherm model (0.9983) compared to the Freundlich isotherm model (0.5007). The experimental data were well fitted with the Langmuir model, where the adsorption of $\mathrm{F}^{-}$is defined as monolayer adsorption onto $\mathrm{GO} / \mathrm{ES}$ adsorbent's surface that is containing a certain number of identical sites [8]. Thus, this indicates, the adsorption of $\mathrm{F}^{-}$is not effective for multilayer adsorption onto the heterogeneous surface (Freundlich model).

Constant parameters of adsorption isotherms that are shown in Table 1 were calculated according to the linearized isotherm models. The empirical constants for Langmuir isotherm, which are $\mathrm{K}_{\mathrm{L}}$ and $\mathrm{q}_{\mathrm{m}}$ were found to be $0.6221 \mathrm{~L} / \mathrm{mg}$ and $46.73 \mathrm{mg} / \mathrm{g}$, respectively. The $\mathrm{K}_{\mathrm{L}}$ constant measured in this study is relatively larger, which indicates a strong affinity between $\mathrm{F}^{-}$(adsorbate) and GO/ES adsorbent [14]. For Freundlich isotherm, the n constant should be obtained in the range of $1-10$, to ensure favorable adsorption [13]. However, the $n$ value in this study is greater than 10 , which agrees with the low $\mathrm{R}^{2}$ value, where the adsorption mechanism of $\mathrm{F}^{-}$onto GO/ES adsorbent is not suitable to represent by Freundlich isotherm. Overall, Langmuir isotherm was very well fitted with this research data, which suggests that the binding energy on the whole surface of the $\mathrm{GO} / \mathrm{ES}$ adsorbent was uniform and the adsorbed $\mathrm{F}^{-}$were adsorbed by forming monolayer adsorption, where sorbate-sorbate interaction can be neglected [13].

\section{Adsorption Kinetics}

The kinetics study of $\mathrm{F}^{-}$adsorption by using GO/ES adsorbent was analyzed by using linearized pseudo-first-order and pseudo-second-order models expressed as in Eq. (5) and (6), respectively with regard to adsorption on the solid surface system [16]. The experimental data obtained were fitted into the models, as illustrated in Fig. 3 and the K values were calculated and tabulated in Table 2.

From Fig. 3, the pseudo-second-order model represents the best $\mathrm{F}^{-}$adsorption kinetic on GO/ES adsorbent compared to Pseudo-first-order, with an $\mathrm{R}^{2}$.

Table 1. Parameters of adsorption isotherms constant

\begin{tabular}{lclc}
\hline \multicolumn{2}{c}{ Langmuir } & \multicolumn{2}{c}{ Freundlich } \\
\hline $\mathrm{q}_{\mathrm{m}}(\mathrm{mg} / \mathrm{g})$ & 46.73 & $\mathrm{n}$ & 32.79 \\
$\mathrm{~K}_{\mathrm{L}}(\mathrm{L} / \mathrm{mg})$ & 0.6221 & $\mathrm{~K}_{\mathrm{F}}$ & 0.4721 \\
$\mathrm{R}^{2}$ & 0.9983 & $\mathrm{R}^{2}$ & 0.5007 \\
\hline
\end{tabular}

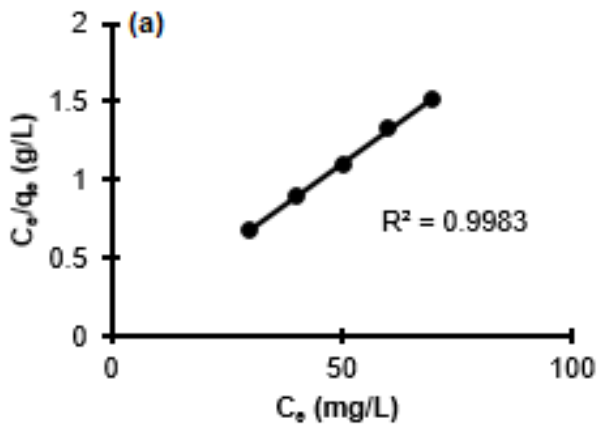

Fig 2. (a) Langmuir and (b) Freundlich isotherms for $\mathrm{F}^{-}$adsorption on GO/ES adsorbent

Table 2. Kinetics parameter for the adsorption of fluoride by GO/ES adsorbent

\begin{tabular}{llll}
\hline \multicolumn{2}{c}{ Pseudo-first-order } & \multicolumn{2}{c}{ Pseudo-second-order } \\
\hline Rate constant $\left(\mathrm{K}_{1}\right)$ & 0.03020 & Rate constant $\left(\mathrm{K}_{2}\right)$ & 0.00047 \\
$\mathrm{R}^{2}$ & 0.95880 & $\mathrm{R}^{2}$ & 0.96970 \\
\hline
\end{tabular}



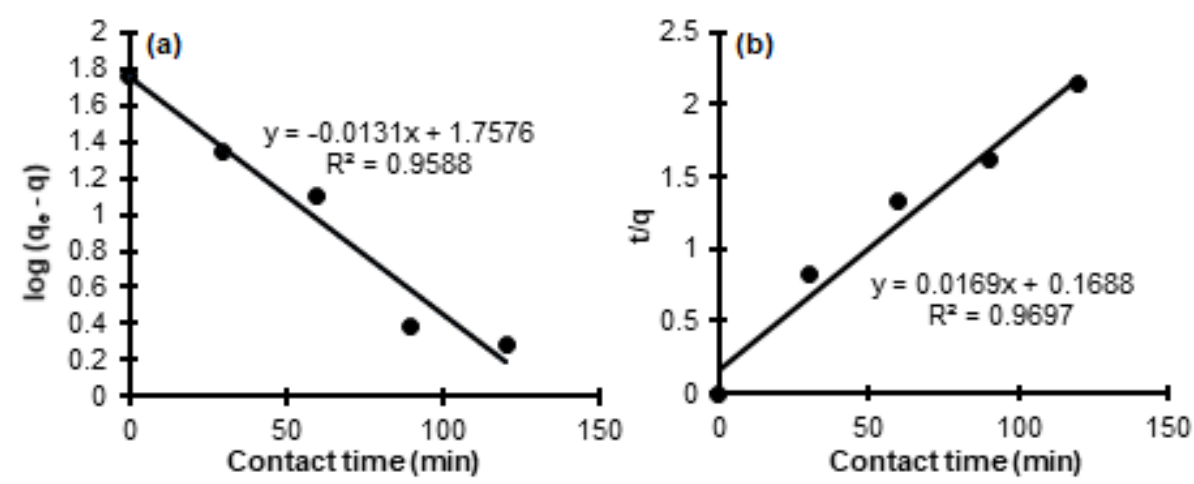

Fig 3. (a) Pseudo-first-order and (b) pseudo-second-order adsorption kinetics models for $\mathrm{F}^{-}$removal by using GO/ES adsorbent

value of 0.9697 and $\mathrm{K}_{2}$ value of 0.00047 . According to pseudo-second-order theory, the adsorption of fluoride onto GO/ES adsorbent is a chemisorption process which involves sharing or exchange of electrons between the adsorbent and $\mathrm{F}^{-}$[13]. There is a possibility that $\mathrm{F}^{-}$may diffuse across a liquid phase prior to GO/ES's active sites through intraparticle diffusion and indirectly reacts with available active sites, such $\mathrm{Ca}^{2+}$ to produce $\mathrm{CaF}$ [17-20].

\section{Adsorption Thermodynamics}

Thermodynamic parameters, such as a change in Gibbs free energy $\left(\Delta \mathrm{G}^{\circ}\right)$, enthalpy $\left(\Delta \mathrm{H}^{\circ}\right)$ and entropy $\left(\Delta S^{\circ}\right)$, were evaluated in this study. $K_{0}$, which is the equilibrium adsorption constant calculated as the ratio between adsorption concentration and equilibrium concentration of the solution is shown in Eq. (7). The Gibbs free energy $\left(\Delta G^{\circ}\right)$ is calculated for adsorption of fluoride onto $\mathrm{GO} / \mathrm{ES}$ adsorbent at all temperatures, where $\mathrm{R}$ is the gas constant $(8.314 \mathrm{~J} / \mathrm{mol} . \mathrm{K})$, and $\mathrm{T}$ is the temperature in Kelvin $(\mathrm{K})$. The experimental data were fitted into the linearized Eq. (9), and illustrated in Fig. 4. All thermodynamic parameters were calculated and tabulated in Table 3.
From Fig. 4, the $\mathrm{R}^{2}$ value obtained is 0.9726 , which is not as high as the previous study done by other researchers [13]. Perhaps, this is due to less adsorption that happened at high temperature $(348.15 \mathrm{~K})$. From Table 3, the positive value of $\Delta \mathrm{G}^{\circ}$ indicates that the process is a physic-sorption process. The values of $\Delta \mathrm{G}^{\circ}$ in between 0 and to $20 \mathrm{~kJ} / \mathrm{mol}$ indicate a physic-sorption process, while the values in between -80 to $-400 \mathrm{~kJ} / \mathrm{mol}$ correspond to the chemisorption process [15]. The increment in values of $\Delta G^{\circ}$ with an increase in temperature suggests that higher temperature makes the

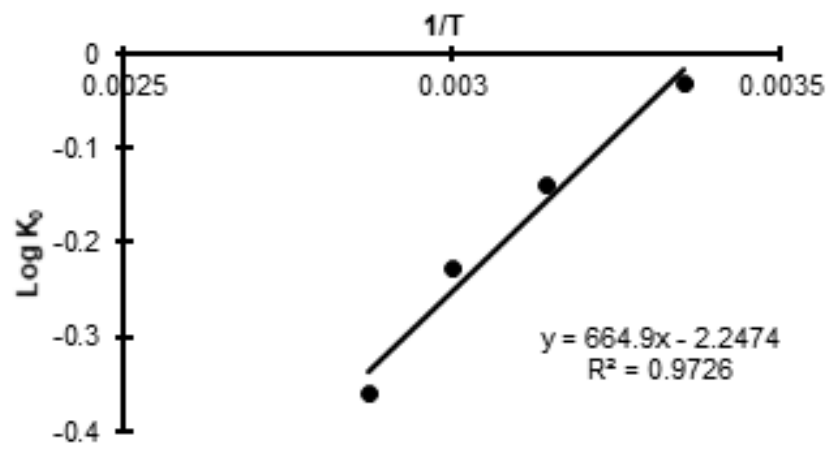

Fig 4. Thermodynamics study of $\mathrm{F}^{-}$adsorption onto GO/ES adsorbent

Table 3. Thermodynamic parameters for the adsorption of $\mathrm{F}^{-}$by GO/ES adsorbent

\begin{tabular}{ccccc}
\hline \multirow{2}{*}{\begin{tabular}{c} 
Temperature \\
\cline { 2 - 5 }
\end{tabular}} & $\mathrm{K}_{0}$ & $\Delta \mathrm{G}^{\circ}(\mathrm{kJ} / \mathrm{mol})$ & $\Delta \mathrm{S}^{\circ}(\mathrm{J} / \mathrm{mol} . \mathrm{K})$ & $\Delta \mathrm{H}^{\circ}(\mathrm{kJ} / \mathrm{mol})$ \\
\cline { 2 - 5 } 298.15 & 0.9275 & 0.1865 & & \\
318.15 & 0.7230 & 0.8581 & -43.04 & -12.73 \\
333.15 & 0.5903 & 1.4560 & & \\
348.15 & 0.4351 & 2.4085 & & \\
\hline
\end{tabular}


adsorption of $\mathrm{F}^{-}$unfavorable, while the negative value of $\Delta S^{\circ}$ indicates that the process is enthalpy driven and the negative value of $\Delta \mathrm{H}^{\circ}$ implies that the adsorption phenomenon is exothermic [12-13,19]. This explains that the adsorption of $\mathrm{F}^{-}$by using GO/ES adsorbent is not suitable to be conducted at high temperature.

\section{- CONCLUSIONS}

In this work, GO/ES adsorbent has been synthesized for $\mathrm{F}^{-}$removal application. The maximum adsorption capacity of $\mathrm{F}^{-}(56 \mathrm{mg} / \mathrm{g})$ was obtained at $25^{\circ} \mathrm{C}, 25 \mathrm{mg} / \mathrm{L}$ of $\mathrm{F}^{-}$initial concentration, $0.05 \mathrm{~g}$ of GO/ES adsorbent dosage and $120 \mathrm{~min}$ of contact time. Adsorption isotherms study show that the experimental data were best fitted with Langmuir isotherm, which indicates that $\mathrm{F}^{-}$adsorption is following monolayer adsorption on a homogenous surface of GO/ES, with an $\mathrm{R}^{2}$ value of 0.9983 . The adsorption kinetics of $\mathrm{F}^{-}$by using $\mathrm{GO} / \mathrm{ES}$ is best presented by the pseudo-second-order model, involving a chemisorption process. From the thermodynamic analysis, $\mathrm{F}^{-}$adsorption by using GO/ES adsorbent is a spontaneous and exothermic process; hence, a higher temperature is not favorable for this process.

\section{- ACKNOWLEDGMENTS}

The authors are grateful for the financial support and facilities provided by Universiti Teknologi MARA (UiTM) to carry out this research work.

\section{- REFERENCES}

[1] Mukherjee, S., and Halder, G., 2018, A review on the sorptive elimination of fluoride from contaminated wastewater, J. Environ. Chem. Eng., 6 (1), 1257-1270.

[2] Jain, P.S., Prasad, S.B.B., and Raghu, A.V., 2017, A short review: Removal of fluoride ions from ground water by using various techniques, IJRG, 5 (4), 98-104.

[3] Nigri, E.M., Cechinel, M.A., Mayer, D.A., Mazur, L.P., Loureiro, J.M., Rocha, S.D., and Vilar, V.J., 2017, Cow bones char as a green sorbent for fluorides removal from aqueous solutions: Batch and fixed-bed studies, Environ. Sci. Pollut. Res., 24 (3), 2364-2380.

[4] Engineering Services Division, 1983, National standard for drinking water quality, Ministry of Health
Malaysia.

[5] Department of Environment Malaysia, 2010, Environmental requirements: A guide for investors, $11^{\text {th }}$ Ed., Ministry of Natural Resources and Environment.

[6] Salifu, A., 2017, Fluoride removal from groundwater by adsorption technology - The occurrence, adsorbent synthesis, regeneration and disposal, Dissertation, Delft University of Technology, Delft, Netherlands.

[7] Kashi, G., Mehree, A., Zaeimdar, M., Khoshab, F., and Madaree, A.M., 2015, Removal of fluoride from urban drinking water by eggshell powder, Bulg. Chem. Commun., 47, 187-192.

[8] Hasan, S.H., Mohan, S., Singh, D.K., and Kumar, V., 2015, Synthesis of graphene oxide and its application for efficient removal of fluoride from water, J. Solid Waste Technol. Manage., 41 (4), 262272.

[9] Kyzas, G.Z., Deliyanni, E.A., and Matis, K.A., 2014, Graphene oxide and its application as an adsorbent for wastewater treatment, J. Chem. Technol. Biotechnol., 89 (2), 196-205,.

[10] Narasimharao, K., Venkata, R.G., Sreedhar, D., and Vasudevarao, V., 2016, Synthesis of graphene oxide by modified Hummers method and hydrothermal synthesis of graphene-NiO nano composite for supercapacitor application, J. Mater. Sci. Eng., 5 (6), 1000284.

[11] Liu, L., Cui, Z., Ma, Q., Cui, W., and Zhang, X., 2016, One-step synthesis of magnetic ironaluminum oxide/graphene oxide nanoparticles as a selective adsorbent for fluoride removal from aqueous solution, RSC $A d v$., 6 (13), 10783-10791.

[12] Mohammad-Rezaei, R., Razmi, H., and DehganReyhan, S., 2014, Preparation of graphene oxide doped eggshell membrane bioplatform modified Prussian blue nanoparticles as a sensitive hydrogen peroxide sensor, Colloids Surf., B, 118, 188-193.

[13] Bhaumik, R., Mondal, M.K., Das, B., Roy, P., Pal, K.C., Das, C., Baneerjee, A., and Datta, J.K., 2012, Eggshell powder as an adsorbent for removal of fluoride from aqueous solution: Equilibrium, 
kinetic and thermodynamic studies, E-J. Chem., 9 (3), 1457-1480.

[14] Raghav, S., and Kumar, D., 2019, Comparative kinetics and thermodynamic studies of fluoride adsorption by two novel synthesized biopolymer composites, Carbohydr. Polym., 203, 430-440.

[15] Swain, S.K., Patnaik, T., Singh, V.K., Jha, U., Patel, R.K., and Dey, R.K., 2011, Kinetics, equilibrium and thermodynamic aspects of removal of fluoride from drinking water using meso-structured zirconium phosphate, Chem. Eng. J., 171 (3), 1218-1226.

[16] Ahamad, K.U., Singh, R., Baruah, I., Choudhury, H., and Sharma, M.R., 2018, Equilibrium and kinetics modeling of fluoride adsorption onto activated alumina, alum and brick powder, Groundwater Sustainable Dev., 7, 452-458.

[17] Sarma, G.K., and Rashid, M.H., 2018, Synthesis of $\mathrm{Mg} / \mathrm{Al}$ layered double hydroxides for adsorptive removal of fluoride from water: A mechanistic and kinetic study, J. Chem. Eng. Data, 63 (8), 2957-2965.

[18] Di, H., Yu, Z., Ma, Y., Pan, Y., Shi, H., Lv, L., Li, F., Wang, C., Long, T., and He, Y., 2016, Anchoring calcium carbonate on graphene oxide reinforced with anticorrosive properties of composite epoxy coatings, Polym. Adv. Technol., 27 (7), 915-921.

[19] Fathy, M., Moghny T.A., Mousa M.A., El-Bellihi A.H.A.A, and Awadallah A.E., 2016, Absorption of calcium ions on oxidized graphene sheets and study its dynamic behavior by kinetic and isothermal models, Appl. Nanosci., 6 (8), 1105-1117.

[20] Kowanga, K.D., Gatebe, E., Mauti, G.O., and Mauti, E.M., 2016, Kinetic, sorption isotherms, pseudofirst-order model and pseudo-second-order model studies of $\mathrm{Cu}$ (II) and $\mathrm{Pb}$ (II) using defatted Moringa oleifera seed powder, J. Phytopharmacol., 5 (2), 7178. 